\title{
Comparing the efficacy and neuroinflammatory potential of three anti-abeta antibodies
}

\author{
James P. Fuller ${ }^{1} \cdot$ Jeffrey B. Stavenhagen $^{2} \cdot$ Søren Christensen $^{2} \cdot$ Fredrik Kartberg $^{2}$ • \\ Martin J. Glennie $^{3} \cdot$ Jessica L. Teeling ${ }^{1}$
}

Received: 5 June 2015 / Revised: 24 September 2015 / Accepted: 25 September 2015 / Published online: 3 October 2015

(C) The Author(s) 2015. This article is published with open access at Springerlink.com

\begin{abstract}
Immunotherapy is a promising strategy for the treatment of Alzheimer's disease (AD). Antibodies directed against Amyloid Beta $(A \beta)$ are able to successfully clear plaques and reverse cognitive deficits in mouse models. Excitement towards this approach has been tempered by high profile failures in the clinic, one key issue has been the development of inflammatory side effects in the brain (ARIAs). New antibodies are entering the clinic for Alzheimer's disease; therefore, it is important to learn all we can from the current generation. In this study, we directly compared 3 clinical candidates in the same pre-clinical model, with the same effector function, for their ability to clear plaques and induce inflammation in the brain. We produced murine versions of the antibodies: Bapineuzumab (3D6), Crenezumab (mC2) and Gantenerumab (chGantenerumab) with an IgG2a constant region. 18-month transgenic APP mice ( $\operatorname{Tg} 2576)$ were injected bilaterally into the hippocampus with $2 \mu \mathrm{g}$ of each antibody or control. After 7 days, the mice tissue was analysed for clearance of plaques and neuroinflammation by histology and biochemical analysis. 3D6 was the best binder to plaques and in vitro, whilst $\mathrm{mC} 2$ bound the least strongly. This translated into 3D6 effectively clearing plaques and reducing the levels of insoluble $\mathrm{A} \beta$, whilst chGantenerumab and $\mathrm{mC} 2$ did not. 3D6 caused a significant increase in the levels of proinflammatory cytokines IL- $1 \beta$ and TNF $\alpha$, and an associated
\end{abstract}

James P. Fuller

jpf1g11@ soton.ac.uk

1 Centre for Biological Sciences, University of Southampton, Southampton, UK

2 Lundbeck A/S, Copenhagen, Denmark

3 Cancer Sciences, University of Southampton, Southampton, UK increase in microglial expression of CD11B and CD68. chGantenerumab increased pro-inflammatory cytokines and microglial activation, but minimal changes in CD68, as an indicator of phagocytosis. Injection of $\mathrm{mC} 2$ did not cause any significant inflammatory changes. Our results demonstrate that the ability of an antibody to clear plaques and induce inflammation is dependent on the epitope and affinity of the antibody.

Keywords Immunotherapy - Alzheimer's disease Bapineuzumab · Gantenerumab · Crenezumab · Inflammation

\section{Introduction}

One neuropathological hallmark of Alzheimer's disease $(\mathrm{AD})$ is the accumulation of amyloid $\beta(\mathrm{A} \beta)$ as extracellular deposits. Data from both familial and sporadic forms of $A D$ led to the hypothesis that $A \beta$ is central to the pathogenesis of $\mathrm{AD}$ [15]. As a result there has been a great effort to develop drugs that will reduce the production of $\mathrm{A} \beta$ or clear the deposits. One approach has been to immunise against $A \beta$, either by active immunisation against $A \beta$ or by passive immunisation with anti- $A \beta$ antibodies. Active immunisation of transgenic APP mice with $A \beta$ clears plaques and reverses memory deficits [25], but active immunotherapy in AD patients is associated with severe inflammatory side effects [20]. Passive immunotherapy with monoclonal anti- $\mathrm{A} \beta$ antibodies also reduces amyloid deposition and reverses cognitive deficiencies in transgenic APP mice [2, 9, 32]. Due to this success in experimental models, several monoclonal antibodies reached clinical trials for the treatment of $\mathrm{AD}$, but excitement towards this approach has been tempered by a 
number of high profile failures to deliver disease-modifying effects. Bapineuzumab and Solanezumab both failed in phase III, and a phase III trial for Gantenerumab was abandoned after a futility analysis [12, 23]. With more antibodies for $\mathrm{AD}$ entering the clinic, including Aducanumab, which has shown promising effects in Phase I, it is imperative to learn from the first-generation antibody therapies to inform the development of new and improved clinical candidates. Bapineuzumab, a humanised $\operatorname{IgG1}$, which recognised the $N$ terminus of $A \beta$ cleared plaques from the brains of patients in a phase II trial, however, it also caused oedema and micro-haemorrhage of the cerebral vasculature $[22,24]$. These side effects limited the top dose in phase III trials, which potentially contributed to the lack of efficacy [23]. These side effects have also been observed with Gantenerumab (hIgG1, N terminus conformational epitope). Pre-clinical studies have suggested that side effects could be due to inflammation caused by $\mathrm{Fc}$ effector function of the therapeutic antibodies, as deglycosylation can prevent vascular damage in vivo $[6,13$, 29]. With this in mind, Crenezumab (hIgG4, mid-domain epitope) was generated with a human IgG4 constant region to modify $\mathrm{Fc}$ effector function and reduce vascular side effects [1].

The efficacy to clear plaques and the potential to induce side effects is difficult to predict due to inconsistent use of experimental models, epitope specificity of the antibody tested ( $\mathrm{N}$, mid or $\mathrm{C}$ terminus) or antibody subclass. In this study, we set out to compare three antibodies which have been in phase III clinical trials for AD: Crenezumab, Bapineuzumab and Gantenerumab. Bapineuzumab is a human IgG1 antibody, which binds to the $\mathrm{N}$ terminus of $\mathrm{A} \beta$ (AA $1-5)$, and can recognise both soluble and insoluble $A \beta$ [23]. Gantenerumab is also a human IgG1 antibody which recognises a conformational epitope, making contact with the $\mathrm{n}$ terminus and the mid-domain of $\mathrm{A} \beta$, reportedly binding more strongly to more aggregated forms compared to soluble $\mathrm{A} \beta$ [3]. Crenezumab is a human IgG4 antibody which recognises a mid-domain epitope (AA 16-24), and binds to all forms of $A \beta$ [1]. We produced murine versions of Crenezumab (mC2), Bapineuzumab (3D6) and a mouse/human chimeric version of Gantenerumab (chGantenerumab) all with an IgG2a constant regions. We compared these antibodies for their ability to clear $A \beta$ plaques and to induce neuroinflammation following intracerebral injection into transgenic APP mice (Tg2576). Murine IgG2a subclass was selected as this subclass is similar to hIgG1 in terms of $\mathrm{Fc} \gamma \mathrm{R}$ binding, and hIgG1 has been the most commonly used subclass for anti-A $\beta$ immunotherapy. Here, we show that the affinity and epitope specificity are important for the efficient removal of $\mathrm{A} \beta$ from the CNS, but also for the induction of a neuroinflammatory response.

\section{Methods}

\section{Recombinant antibody production}

Antibody primary sequences for the variable domains of 3D6, Gantenerumab and $\mathrm{mC} 2$ along with sequences for the constant regions of the mouse $\operatorname{IgG} 2 \mathrm{a}$ heavy chain and mouse kappa light chain were identified from the public domain. Synthetic genes for the variable light chain-murine Kappa constant domain and variable heavy chain-mIgG2a constant domain were sub-cloned into the pTT5 plasmid for transient gene expression (Geneart). Primary structures of the expressed antibodies are shown in Table 1. Transfection of heavy chain and light chain expression vectors was performed in HEK293 6E cells using PEIpro (Polyplus) as a transfection reagent. The HEK293 6E expression system including the pTT5 vector is licensed from the National Research Council of Canada. Transfected cells were cultured until the viability had dropped to around $50 \%$ and culture media harvested by centrifugation and ultrafiltration. Antibodies were purified from clarified culture media by protein-G Sepharose (GE healthcare) affinity chromatography followed by online desalting into PBS (Invitrogen) using ÄKTA express system and standard protocols for monoclonal antibody purification. Finally, the antibodies were sterile filtered using 0.2- $\mu \mathrm{m}$ filters (Millipore) and kept at $4{ }^{\circ} \mathrm{C}$. Purified antibodies were analysed for purity by SDS-PAGE and Bioanalyzer 2000, aggregation by uplc-sec (Waters), concentration by Pierce BCA kit (ThermoFisher) and endotoxin by endosafe PTS (all <0.025 EU/ $\mathrm{mg}$, Charles River). Confirmation of the primary structure was done by analysing the intact mass of the heavy chain and light chain by RP-uplc (C4 column in $0.1 \% \mathrm{FA}$; ACN gradient) followed by ESI-MS on a QTOF instrument (Waters XEVO QTOF). Multicharged spectra were processed using the MaxEnt 1 deconvolution algorithm.

\section{Abeta Binding assay}

Binding characteristics of the recombinant antibodies to $A \beta$ peptide was assessed as follows: 96-well Maxisorp plates (Nunc, Denmark) were coated with $100 \mu \mathrm{l}$ of $0.1 \mu \mathrm{g} / \mathrm{ml} \mathrm{A} \beta$ 1-40 peptide (America Peptide, Sunnyvale, CA) in bicarbonate buffer ( $\mathrm{pH}$ 9.6) overnight at room temperature. Plates were washed 5 times with PBS/ $0.1 \%$ Tween and recombinant anti-A $\beta$ antibodies were serially diluted in $100 \mu \mathrm{l}$ of assay buffer (PBS/1 \% BSA) and incubated for $1 \mathrm{~h}$ at room temperature. After washing plates 5 times with $\mathrm{PBS} / 0.1 \%$ tween, antibody binding was detected by the addition of $100 \mu \mathrm{l}$ of using horse anti-mouse $\mathrm{IgG}$ conjugated to biotin (vector) diluted 1:200 in assay buffer. Plates were washed 5 times before addition of $100 \mu \mathrm{l}$ streptavidin poly-HRP 


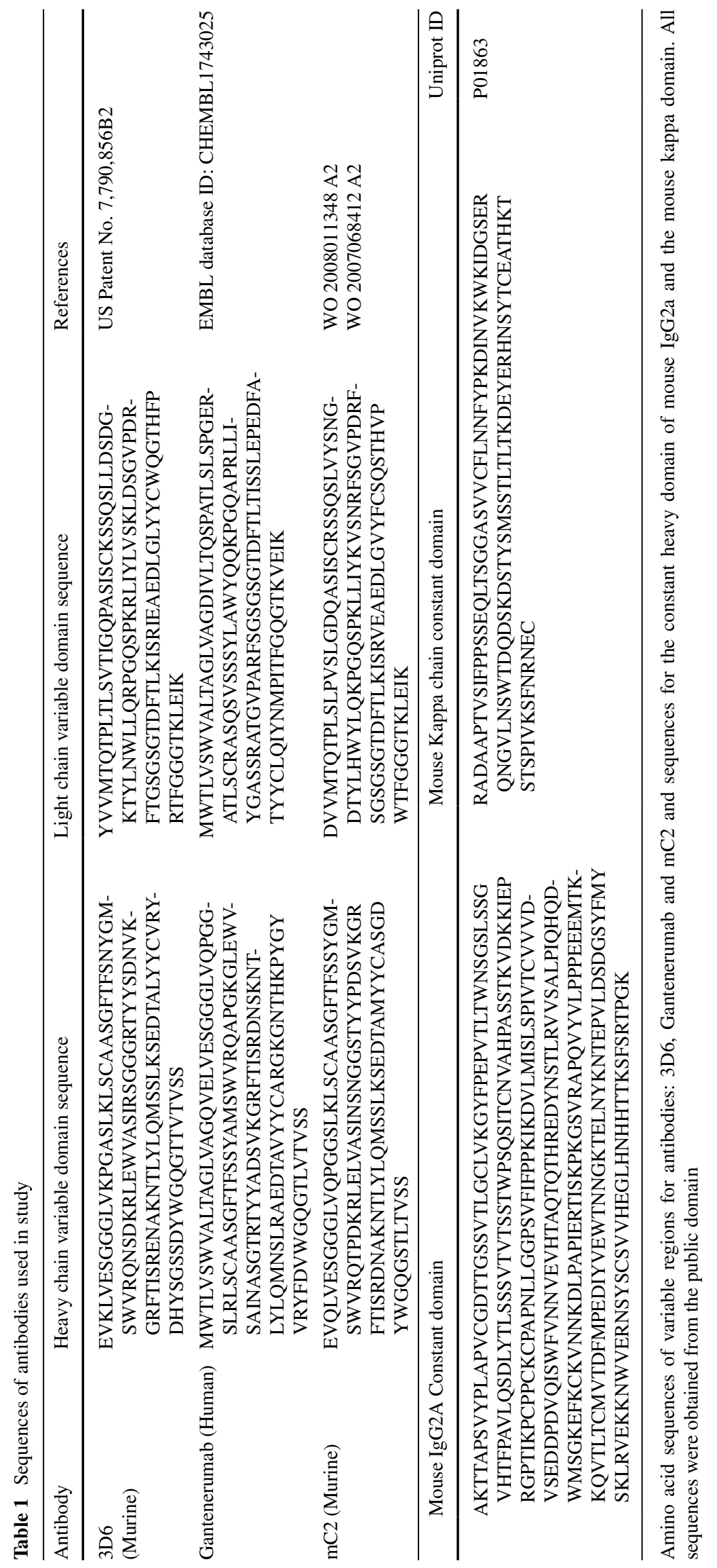


(1:10,000 in assay buffer, Sanquin, the Netherlands). Bound antibody was detected using tetramethylbenzidine (TMB) (Sigma) as a substrate. The substrate solution was made by dissolving 1 TMB tablet in $1 \mathrm{ml}$ of DMSO, which was made up to $10 \mathrm{ml}$ in phospho-citrate buffer (Sigma), $2 \mu \mathrm{l}$ of $30 \% \mathrm{H}_{2} \mathrm{O}_{2}$ (Sigma) was added to the solution directly before addition to the plate. $100 \mu \mathrm{l}$ of the substrate solution was added to each well and allowed to develop. The reaction was stopped by the addition of $50 \mu \mathrm{H}_{2} \mathrm{SO}_{4}$ to each well, and absorbance was measured at $450 \mathrm{~nm}$ using a Fluostar Optima ${ }^{\mathrm{TM}}$ spectrophotometer.

\section{Cell culture and effector function Assay}

The mouse macrophage cell line RAW 264.7 was cultured in DMEM media (Gibco) supplemented with $10 \%$ heat inactivated foetal calf serum (FCS, Sigma) and $2 \mathrm{mM}$ glutamine (Sigma). Cells were incubated at $37{ }^{\circ} \mathrm{C}$ with $5 \%$ $\mathrm{CO}_{2}$. Effector function of the recombinant antibodies was measured in vitro by immobilising antibodies $(100 \mu \mathrm{l} /$ well, $5 \mu \mathrm{g} / \mathrm{ml}$ antibody in $\mathrm{pH} 9.6$ bicarbonate buffer) to U.V. sterilised 96 well ELISA plates (Nunc, Maxisorp Flat bottom). Unbound antibodies were removed by washing the plates with DMEM, plates were then blocked with cell culture medium containing $10 \%$ FCS for $1 \mathrm{~h}$, then $4 \times 10^{4}$ RAW cells per well were added in DMEM media containing 100 units per $\mathrm{ml}$ of murine IFN- $\gamma$ (Peprotech). The cells were cultured for $24 \mathrm{~h}$ and supernatant removed to measure the levels of TNF $\alpha$ by ELISA.

\section{TNF $\alpha$ ELISA}

$\mathrm{TNF} \alpha$ levels were measured in cell culture supernatant using TNF $\alpha$ duoset $^{\mathrm{TM}}$ ELISA (RnD systems), according the manufacturer's instructions, with minor modification. Briefly, capture antibodies were coated onto maxisorp plates in $100 \mu \mathrm{l} 0.1 \mathrm{M}$ bicarbonate buffer $\mathrm{pH} 9.4$ overnight at room temperature. The plates were washed 5 times in PBS $0.05 \%$ Tween. Cell culture supernatant or TNF $\alpha$ standard serially diluted in assay buffer (PBS/1 \% BSA) was added and plates incubated for $2 \mathrm{~h}$ on a shaking table. After washing the plates, the secondary biotinylated antibody was added incubated for a further $2 \mathrm{~h}$, before the addition of poly-HRP (1:10000 in PBS/1 \%BSA, Sanquin, the Netherlands). This assay was developed and measured in the same way as the $A \beta$ binding ELISA.

\section{Animals and stereotaxic surgery}

Female $\operatorname{Tg} 2576$ transgenic mice possessing a copy of human APP with the Swedish double mutate on (KM670/671NL) were obtained from Taconic and aged to 18 months. Mice were kept in $12 \mathrm{~h}$ light-dark cycles with free access to food and water. Mice were randomised into 4 groups (3D6, mC2, Gantenerumab or irrelevant mIgG2a control ( $n=6 / 7$ per treatment group). Mice were weighed and anaesthetised using sevoflurane, and secured onto a stereotaxic frame. A mid-sagittal incision was made exposing the skull, and two burr holes were made at coordinates $(-2.0,+1.7)$ and $(-2.0,-1.7)$. A fire pulled glass capillary with a diameter of $<50 \mu \mathrm{m}$ (Sigma) was inserted $-1.4 \mathrm{~mm}$ into the brain and $2 \mu \mathrm{l}$ of antibody $(1 \mathrm{mg} / \mathrm{ml})$ was slowly injected bilaterally. This method allows accurate injection of $2 \mu \mathrm{g}$ of $\mathrm{mAb}$ with minimal mechanical damage. Sutures were used to close scalp and mice were left to recover in a thermo-regulated environment. All procedures were carried out in accordance with Danish law.

\section{Tissue processing}

Seven days after the injections the mice were terminally anaesthetised using avertin, and transcardially perfused with heparinised saline. The brain was removed and cut to two hemispheres. The left hemisphere was further dissected, and a hippocampal punch was taken as described before [16] and frozen in isopentane over dry ice. The right hemisphere was mounted in optimal cutting temperature medium (OCT, Sakura Finetek, Thatcham, UK) for immunohistochemistry.

\section{Immunohistochemistry}

Brains were cut into 10 micron sections using a cryostat. A series of sections through the hippocampus was taken, and the site of injection was located by staining for CD11B; this allowed identification of the antibody-injected brain region to use for further immunohistochemistry. Immunohistochemistry was performed as described before [27] using CD11B (5C6, 1:500, Serotec), CD68 (FA11, 1:500, Serotec) and $\mathrm{A} \beta$ (3D6, 1:1000, in house), FITC sheep anti-mouse $F(a b) 2$ (1:500, Sigma), horse anti-mouse biotinylated (1:250, Vector) and rabbit anti rat biotinylated (1:250, Vector).

\section{Congo red staining}

Ten micron sections were dried at $37{ }^{\circ} \mathrm{C}$ for $30 \mathrm{~min}$, and fixed in $4{ }^{\circ} \mathrm{C}$ ethanol for $15 \mathrm{~min}$ before washing in three changes of PBS. Sections were stained for $15 \mathrm{~min}$ in $0.3 \%$ Congo red (Sigma) in $80 \%$ ethanol containing $0.01 \%$ $\mathrm{NaOH}$ (Sigma). Sections were de-stained by dipping five times in $50 \%$ ethanol containing $0.02 \% \mathrm{NaOH}$, and transferred into PBS. Slides were mounted using Pro-long gold $^{\mathrm{TM}}$ anti-fade reagent (Invitrogen) containing the counterstain DAPI. 


\section{$A \beta$ staining in human tissue}

The postmortem tissue of the $\mathrm{AD}$ cases was provided by BRAIN UK under the ethics approval obtained from the National Research Ethics Committee South Central Hampshire B (REC reference 14/SC/0098). Formalin-fixed paraffin-embedded brain tissue was cut into $5 \mu \mathrm{m}$ sections on a microtome. Tissue was dewaxed in clearene (Surgipath), and rehydrated in graded alcohols. Endogenous peroxidase activity was quenched by incubation of tissue with $3 \%$ $\mathrm{H}_{2} \mathrm{O}_{2}$ in methanol for $10 \mathrm{~min}$, before 3 washes with trisbuffered saline (TBS). Sections were then either incubated for $30 \mathrm{~min}$ in $80 \%$ formic acid (Fisher) or in TBS. Sections were blocked for 30 min with medium containing DMEM, FCS BSA. Anti-A $\beta$ antibodies were added at a concentration of 1:1000 in TBS and incubated at $4{ }^{\circ} \mathrm{C}$ overnight. Sections were then washed in 3 rinses of TBS before addition of biotinylated rabbit anti-mouse IgG secondary (Abcam, 1:600) and incubated for $1 \mathrm{~h}$. Bound antibody was detected by incubation for 30 min with $\mathrm{ABC}$ system (Vector), and washed 3 times in TBS, before developing with diaminobenzidine solution (DAB, Vector). Slides were dehydrated in graded alcohols into clearene, before mounting with pertex ${ }^{\mathrm{TM}}$ (Cellpath).

\section{Quantification of Immunohistochemistry}

Light microscopy (DAB) and fluorescent images were taken on a Leica DM5000 microscope using QWIN or LAS software. The quantification of DAB images was performed using the freeware-ImageJ. Images taken with a $20 \times$ objective were de-convoluted using HDAB RGB values, which split images into haematoxylin and DAB channels. The DAB staining was turned into a binary image, and the percentage area above a marker-specific threshold was measured. To quantify congophilic plaques, the number of Congo red-positive deposits was counted in the hippocampus. The number of plaques was then normalised to hippocampal area. During all quantification, the slides were blinded to prevent bias.

\section{MSD measurement of A $\beta$ and cytokines}

Protein was extracted from hippocampal punches in 2 stages, as described previously [26]. First, hippocampal tissue was placed in a buffer containing: $150 \mathrm{mM} \mathrm{NaCL}$, $25 \mathrm{mM}$ TRIS $1 \%$ triton $\mathrm{x}-100$ and complete mini protease inhibitors (Roche). The tissue was mechanically homogenised and the homogenate was centrifuged at 20,000 $\mathrm{g}$ at $4{ }^{\circ} \mathrm{C}$ for $1 \mathrm{~h}$ to remove insoluble material. The supernatant from this fraction was used to measure pro-inflammatory cytokine levels and the triton soluble $A \beta$ fraction using multiplex MSD technology. The pellet was re-suspended in
$70 \%$ formic acid and incubated for $15 \mathrm{~min}$ to solubilise aggregated forms of $\mathrm{A} \beta$, this solution was neutralised in 20 volumes of pH8 TRIS, and centrifuged at 20,000 $\mathrm{g}$ for $1 \mathrm{~h}$ and the supernatant used to measure the formic acid soluble $\mathrm{A} \beta$ fraction. Total protein levels were measured by $\mathrm{BCA}$ protein assay (Pierce), and final levels were expressed as $\mathrm{pg} / \mathrm{mg}$ protein. The multiplex $A \beta$ assay c-terminal antibodies to capture specific $A \beta$ peptides, and uses the antibody 6E10 (AA 1-16) for detection.

\section{Statistical analysis}

All data are expressed as mean \pm standard deviation. Statistical analysis was performed and figures created using Graphpad Prism software. Data were first analysed for normal distribution; normally distributed data were analysed by one-way ANOVA and then treatment groups were compared using TUKEY post hoc analysis. Non-parametric data were analysed using non-parametric equivalents.

\section{Results}

\section{Antibody characterisation}

Three murine anti-A $\beta$ antibodies: 3D6, $\mathrm{mC} 2$ and chGantenerumab were generated recombinantly from the variable domain amino acid sequences. All antibodies were produced with the same mouse IgG2a constant regions, to ensure they had the same effector function. The antibodies were purified and free from endotoxin and $\mathrm{IgG}$ aggregates prior to use in experiments. 3D6 and $\mathrm{mC} 2$ were the original parent antibodies of Bapineuzumab and Crenezumab.

First, the specificity and relative affinity to $A \beta$ were tested by measuring binding to immobilised $A \beta$ 1-40 peptide. Figure $1 \mathrm{~b}$ shows that both 3D6 and bind to recombinant peptide with relative high affinity (EC50 $3 \mathrm{D} 6=0.17 \mathrm{pM}$; EC50 chGantenerumab $=0.34 \mathrm{pM}$ ), however, 100-fold higher levels of $\mathrm{mC} 2$ were required to reach half maximal binding $(\mathrm{EC} 50 \mathrm{mC} 2=17.4 \mathrm{pM}$ ), suggesting significantly lower affinity to immobilised $A \beta$. Antibodies were then tested for binding to $A \beta$ plaques in brain sections from $\mathrm{Tg} 2576$ mice, and to better mimic in vivo binding conditions tissue sections were not subjected to any antigen retrieval before immuno-staining. 3D6 bound plaques in tissue obtained from $\mathrm{Tg} 2576$, while no binding was observed in wild-type mice. $\mathrm{mC} 2$ also bound but fewer plaques were labelled (Fig. 1c). chGantenerumab labelled plaques, however, it also appeared to bind to neurons in both $\mathrm{Tg} 2576$ and wild-type mice. All antibodies were produced as $\operatorname{IgG} 2 \mathrm{a}$ isotype, using the same constant region, and therefore should all have the same ability to bind and activate Fc $\gamma$ Rs. We then tested the ability of these 
(a)

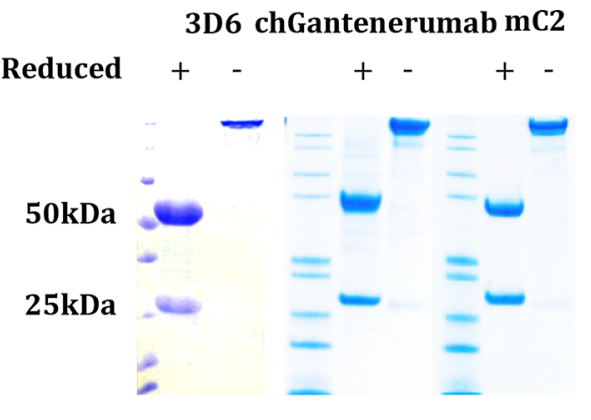

(c)

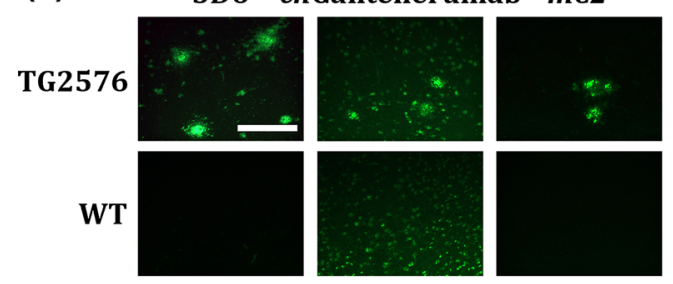

(e)

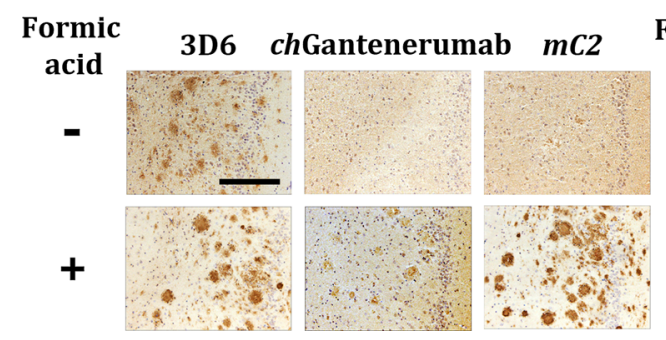

Fig. 1 In vitro binding and effector function of 3D6 chGantenerumab and $\mathrm{mC} 2$. a Purified recombinant antibodies were separated by reduced and non-reduced polyacrylamide electrophoresis. Non-reduced antibodies run as a single band, reduced antibodies break into heavy and light chain fragments $(50,25 \mathrm{kDa}$ respectively). b Binding of anti-A $\beta$ antibodies to immobilised $A \beta_{1-40}$. 3D6 and chGantenerumab both bind with relatively high affinity (EC50 3D6 $=0.17 \mathrm{pM}$; EC50 chGantenerumab $=0.34 \mathrm{pM}) \mathrm{mC} 2$ bound with lower relative affinity $(\mathrm{EC} 50 \mathrm{mC} 2=17.4 \mathrm{pM})$. c Binding of 3D6, chGantenerumab and $\mathrm{mC} 2$ to $\mathrm{Tg} 2576$ (APP) and wild-type

antibodies to bind to plaques in $\mathrm{Tg} 2576$ tissue sections with and without formic acid antigenic retrieval (Fig. 1e). Formic acid treatment breaks down aggregated $\mathrm{A} \beta$ into more soluble species. We found that 3D6 was able to bind to plaques without any antigen retrieval, but $\mathrm{mC} 2$ and chGantenerumab could not. After formic acid treatment, mC2 labelled plaques very well and chGantenerumab labelled them faintly. The conformation of $\mathrm{A} \beta$ in $\mathrm{Tg} 2576$ mice and human $\mathrm{AD}$ cases may be different, and this has previously been reported to affect target engagement of anti-A $\beta$ antibodies [28]. To characterise the ability of antibodies to bind to $\mathrm{A} \beta$ from human cases, brain sections from $\mathrm{AD}$ cases were stained with and without formic acid antigenic (b)

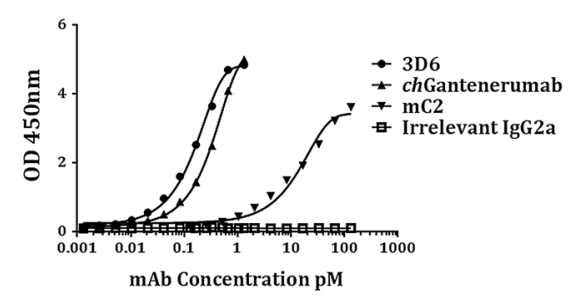

(d)

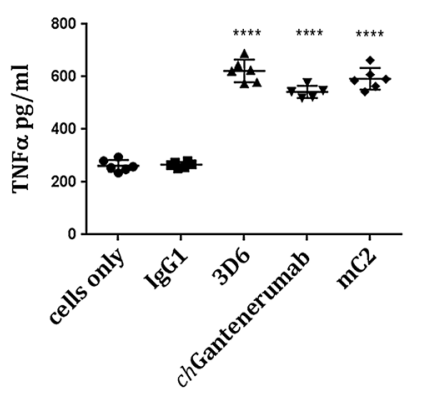

(f)

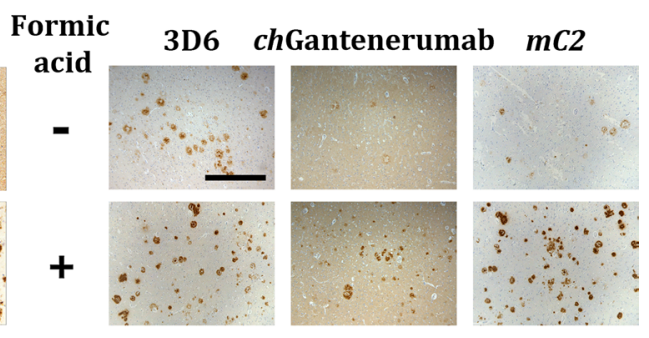

(WT) brain sections. d TNF $\alpha$ levels produced by RAW264.7 cells in response to immobilised $\mathrm{A} \beta$ antibodies or IgG1 control. Data analysed by one-way ANOVA and Tukey post hoc test, and expressed as mean $\mathrm{pg} / \mathrm{ml}$ supernatant \pm standard deviation (SD, $n=6)$. Data is representative of 3 independent experiments $(* * * * p<0.0001)$. e Binding of antibodies to formalin-fixed tissue from $\operatorname{Tg} 2576$ mice, with and without formic acid antigenic retrieval. $\mathbf{f}$ Binding of antibodies to human AD brain tissue, with and without formic acid antigen retrieval

retrieval (Fig. 1f). The results were comparable to $\mathrm{Tg} 2576$ tissue, with 3D6 able to bind plaques without antigenic retrieval, but staining improved after formic acid treatment. The antibody $\mathrm{mC} 2$ bound poorly without formic acid but labelled plaques well after treatment. chGantenerumab again showed background staining, but plaque binding was evident after formic acid treatment. Using an Fc $\gamma \mathrm{R}$ crosslinking assay, we tested the ability of each antibody to activate macrophages in vitro. All $\operatorname{IgG} 2 \mathrm{a}$ anti-A $\beta$ antibodies stimulate secretion of the cytokine $\mathrm{TNF} \alpha$ compared to cell only controls, while mouse IgG1, a subclass which has lower affinity for activating Fc $\gamma$ R, fails to induce TNF $\alpha$ secretion (Fig. 1d). In summary, 3D6 binds plaques and 

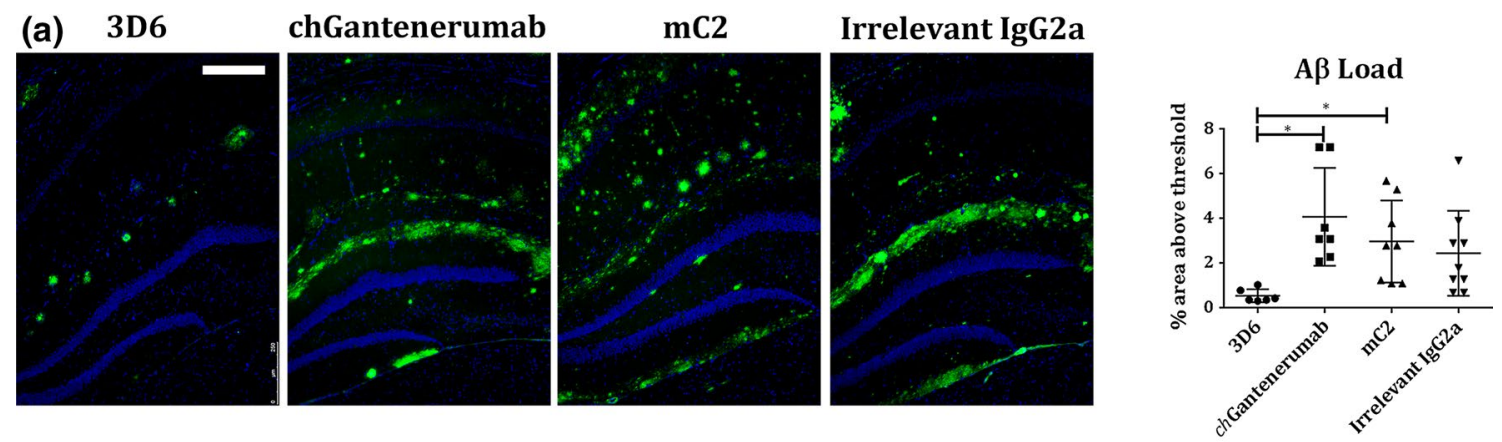

(b) $3 \mathrm{D} 6$

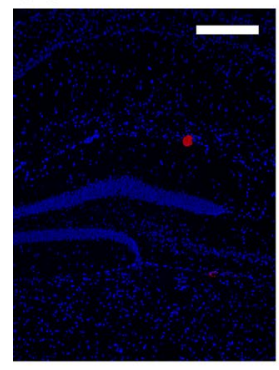

chGantenerumab

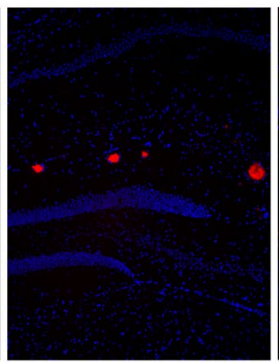

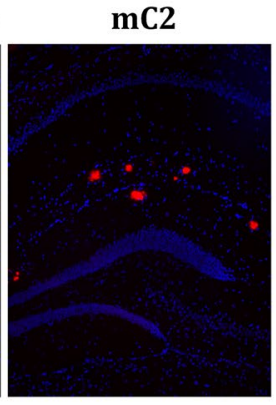

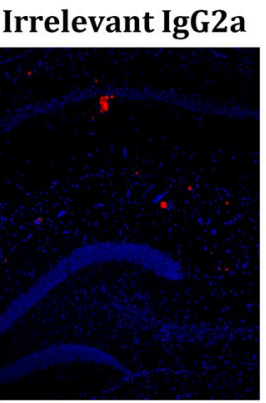

\section{Congophillic plaques}

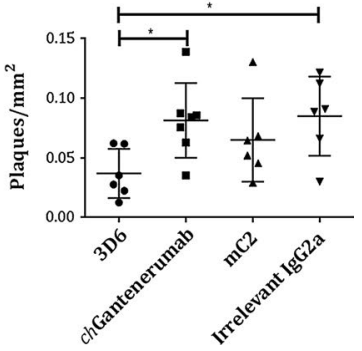

Fig. 2 Anti-A $\beta$ immunohistochemistry and congophilic plaque load. a Tissue sections from $\mathrm{Tg} 2576$ mice injected with antibodies were immuno-stained for $A \beta$, and the percentage staining area above threshold was measured. Data were analysed by Kruskal-Wallis and Dunn's post hoc test and expressed as mean \pm SD $(n=6 / 7)$. 3D6 significantly reduced $\mathrm{A} \beta$ load compared to $\mathrm{mC} 2$ and $c h$ Gantenerumab ( $p=0.0265$ and $p=0.0013$, respectively). Images taken with a $\times 10$ objective, scale bar $250 \mu \mathrm{m}$. b To test for clearance of congophilic

recombinant $\mathrm{A} \beta$ 1-40 peptide with high affinity and specificity, $\mathrm{mC} 2$ selectively binds $\mathrm{A} \beta$ but with lower affinity, while chGantenerumab binds $\mathrm{A} \beta$ 1-40 peptide with high affinity, in situ binding indicates non-specific binding to neurons. All antibodies have the comparable ability to activate macrophages through Fc $\gamma$ Rs.

\section{Clearance of $\mathbf{A} \beta$}

Next, we tested the ability of the anti-A $\beta$ antibodies to clear $\mathrm{A} \beta$ in vivo by injecting $2 \mu \mathrm{g}$ of each antibody into the hippocampus of 18-month-old Tg2576 mice. Clearance of $\mathrm{A} \beta$ after intracerebral injection of antibody into $\mathrm{Tg} 2576$ mice was quantified by $A \beta$ immuno-staining. Injection of 3D6 significantly reduced $A \beta$ plaque load in comparison to $c h$ Gantenerumab and $\mathrm{mC} 2$ (Fig. 2a, $p=0.0013$ and $p=0.026$, respectively). Due to the potential of antigenic masking by injected antibodies, Congo red staining was used to detect the clearance of congophilic deposits after antibody injection. 3D6 significantly reduced the number of Congo red-positive plaques in the hippocampus compared to irrelevant $\operatorname{IgG} 2 \mathrm{a}$ and $c h$ Gantenerumab injected animals (Fig. $2 \mathrm{~b}, p=0.0265$ and $p=0.0178$, respectively). The plaques, brain sections from were stained with Congo red. The numbers of congophilic plaques were counted and normalised to hippocampal area and expressed as congophilic plaques $/ \mathrm{mm}^{2}$. Data were analysed by one-way ANOVA and Tukey post hoc test and expressed as mean $\pm \mathrm{SD}(n=6 / 7)$. 3D6 significantly reduced the number of congophilic plaques compared to irrelevant IgG2a and chGantenerumab $(p=0.0265$ and $p=0.0178$, respectively). Images taken with a $\times 10$ objective, scale bar $250 \mu \mathrm{m}$

results were confirmed by measuring the levels $A \beta 38, A \beta 40$ and $A \beta 42$ in brain homogenate. Diffuse (triton soluble) $A \beta$ levels were not affected 7 days post-injection. Supporting the decreased immuno-staining, 3D6 significantly reduced the amount of aggregated (formic acid soluble) A $\beta 38$ compared to Gantenerumab or irrelevant IgG2a injection (Fig. 3d, $p=0.0168$ and $p=0.0073$, respectively). 3D6 also significantly lowered the amount of aggregated A $\beta 42$ compared to irrelevant IgG2a (Fig. 3f, $p=0.041$ ), and cleared aggregated $A \beta 40$ in $50 \%$ of mice treated with this antibody (Fig. 3e). chGantenerumab and $\mathrm{mC} 2$ did not induce significant changes to aggregated $\mathrm{A} \beta$ levels.

\section{Inflammatory changes}

Neuroinflammation is thought to be a main cause of side effects in patients treated with anti-A $\beta$ antibodies, therefore, we compared the ability of each of the antibody to induce inflammation after intracerebral injection. We first analysed changes in microglial phenotype by immunohistochemistry. Injection of 3D6 induced a significant increase in the expression of microglial marker CD11B, compared to injection with $\mathrm{mC} 2$ and irrelevant IgG2a (Fig. 4a-h, 
(a) Triton soluble Aß38

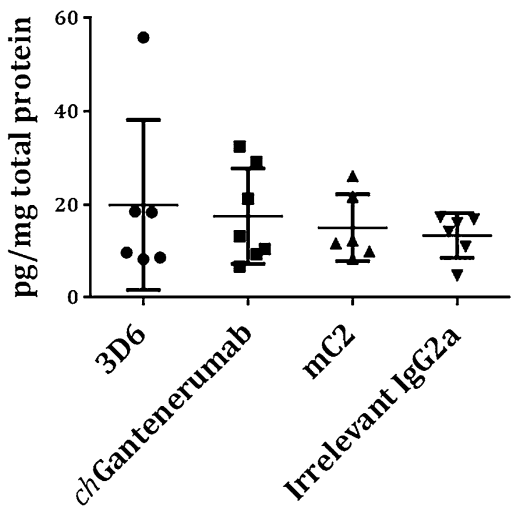

(d)

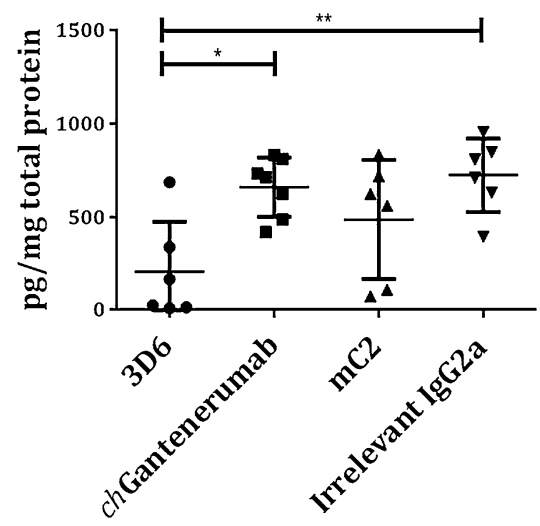

(b) Triton soluble Aß40

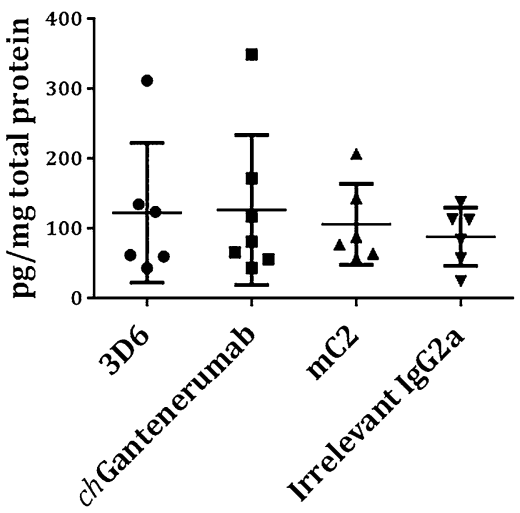

(e)

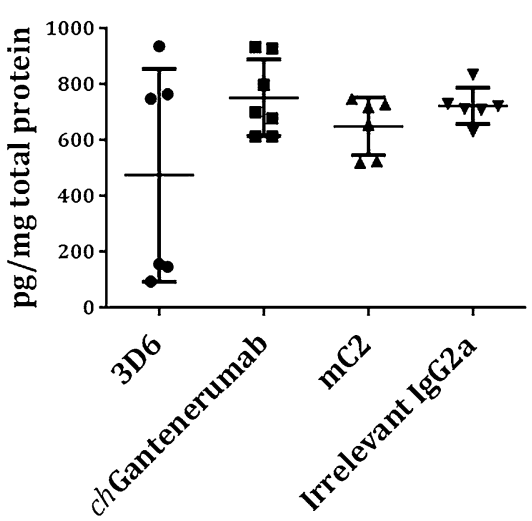

(c) Triton soluble Aß42

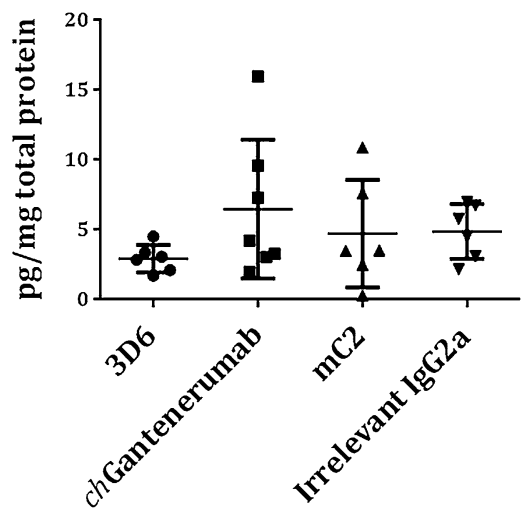

(f) $\quad$ FA soluble Aß42

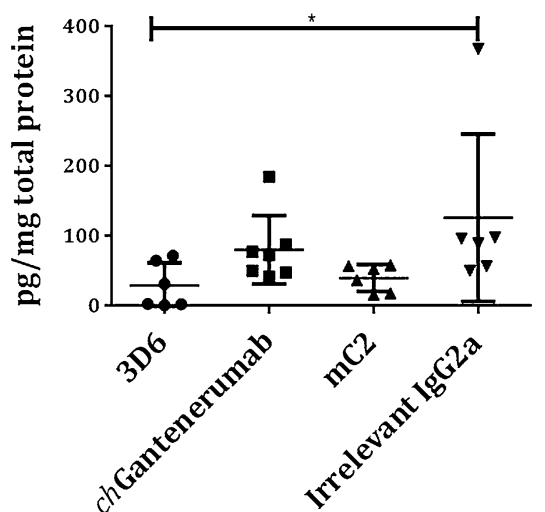

Fig. 3 Soluble and insoluble $A \beta$ levels measured by multiplex ELISA. The levels of 3 different $A \beta$ peptides were measured by multiplex ELISA from two different fractions of brain homogenate: triton soluble and formic acid soluble. $\mathrm{A} \beta$ concentration was normalised to total protein levels and expressed as $\mathrm{pg} / \mathrm{mg}$ total protein. a-c Levels of triton soluble $A \beta 38, A \beta 40$ and $A \beta 42$, respectively. d-f Levels of formic acid soluble $A \beta 38, A \beta 40$ and $A \beta 42$, respectively. With the $p=0.0023$ and $p=0.0017$, respectively). chGantenerumab also induced $\mathrm{CD} 11 \mathrm{~B}$ upregulation in comparison to $\mathrm{mC2}$ and irrelevant $\operatorname{IgG} 2 \mathrm{a}(p=0.0093$ and $p=0.007$, respectively). We have previously shown CD11B to be upregulated after IgG immune complex formation in the brain [27], suggesting that the increase in CD11B may be due to $F c \gamma R$ binding and subsequent activation of microglia. To assess phagocytic activity, we analysed expression levels of CD68 and detected an increased CD68 expression on microglia in 3D6 injected animals, but not in chGantenerumab injected animals, although the increase was not significantly different (Fig. $4 \mathrm{i}-\mathrm{p}, p=0.08$ ). Figure $4 \mathrm{q}-\mathrm{x}$ shows staining for mouse $\mathrm{IgG}$, and there is evidence of target engagement by all three of the anti- $\mathrm{A} \beta$ antibodies following intracranial injection, as plaques are positive for IgG. Quantification shows that $c h$ Gantenerumab has significantly higher levels of IgG than control injected animals exception of $\mathbf{e}$, data were analysed by one-way ANOVA with Tukey post hoc test e was analysed by Kruskal-wallis and Dunn's post hoc. Data is expressed as mean $\pm \mathrm{SD}(n=6 / 7)$. 3D6 significantly reduced the amount of formic acid soluble $\mathrm{A} \beta 38$ compared to chGantenerumab and irrelevant $\operatorname{IgG} 2 \mathrm{a}$ control $(p=0.0168$ and $p=0.0073$, respectively) and reduced levels of formic acid soluble $A \beta 42$ compared to irrelevant IgG2a (Fig. 3f, $p=0.041$ )

(Fig. $4 \mathrm{q}-\mathrm{x}, p=0.011$ ). Unlike in vitro binding assays, there was no evidence of the $c h$ Gantenerumab binding to neurons.

We showed that in vitro, all three $A \beta$ antibodies engage $\mathrm{Fc} \gamma \mathrm{Rs}$ resulting in macrophage activation and TNF $\alpha$ secretion. Therefore, we next investigated the neuroinflammatory potential in vivo. Injection of 3D6 leads to significantly increased levels of pro-inflammatory cytokines $\mathrm{TNF} \alpha$ and IL-1 $\beta$ compared to IgG2a control (Fig. 5a, b, $p=0.0042$, $p=0.0262$ ). Increased levels of KC/GRO in 3D6 injected animals were observed, although this did not reach significance (Fig. $5 \mathrm{~d}, p=0.10$ ). Injection of chGantenerumab also results in increased neuroinflammation, while $\mathrm{mC} 2$ did not affect any cytokine levels measured. These observations suggest that high affinity $\operatorname{IgG} 2 \mathrm{a}$ anti-A $\beta$ antibodies reduce $A \beta$ load but this is associated with increased neuroinflammation. 
Fig. 4 Expression of microglial activation markers after antibody injection. Expression of microglial markers CD11B and CD68 and IgG distribution in the hippocampus 7 days after injection of anti-A $\beta$ antibodies. $\mathbf{a}-\mathbf{h}$ Representative images of CD11B expression. i-p Representative images of CD68. $\mathbf{q}-\mathbf{x}$ Representative images of IgG distribution. $\mathbf{y}-\mathbf{a b}$ No primary control sections. Pictures are taken with a $5 \times$ objective and $40 \times$ objective, scale bars 100 and $800 \mu \mathrm{m}$, respectively. Staining was quantified as area above threshold of staining and analysed by one-way ANOVA and Tukey post hoc test $(n=6 / 7)$. 3D6 induced a significant increase in the expression of CD11B, compared to injection with $\mathrm{mC} 2$ and irrelevant IgG2a (Fig. 4a-h, $p=0.0023$ and $p=0.0017$, respectively). chGantenerumab also induced CD11B upregulation in comparison to $\mathrm{mC} 2$ and irrelevant $\operatorname{IgG} 2 \mathrm{a}(p=0.0093$ and $p=0.007$, respectively). chGantenerumab has significantly higher levels of IgG than control injected animals $(p=0.011)$

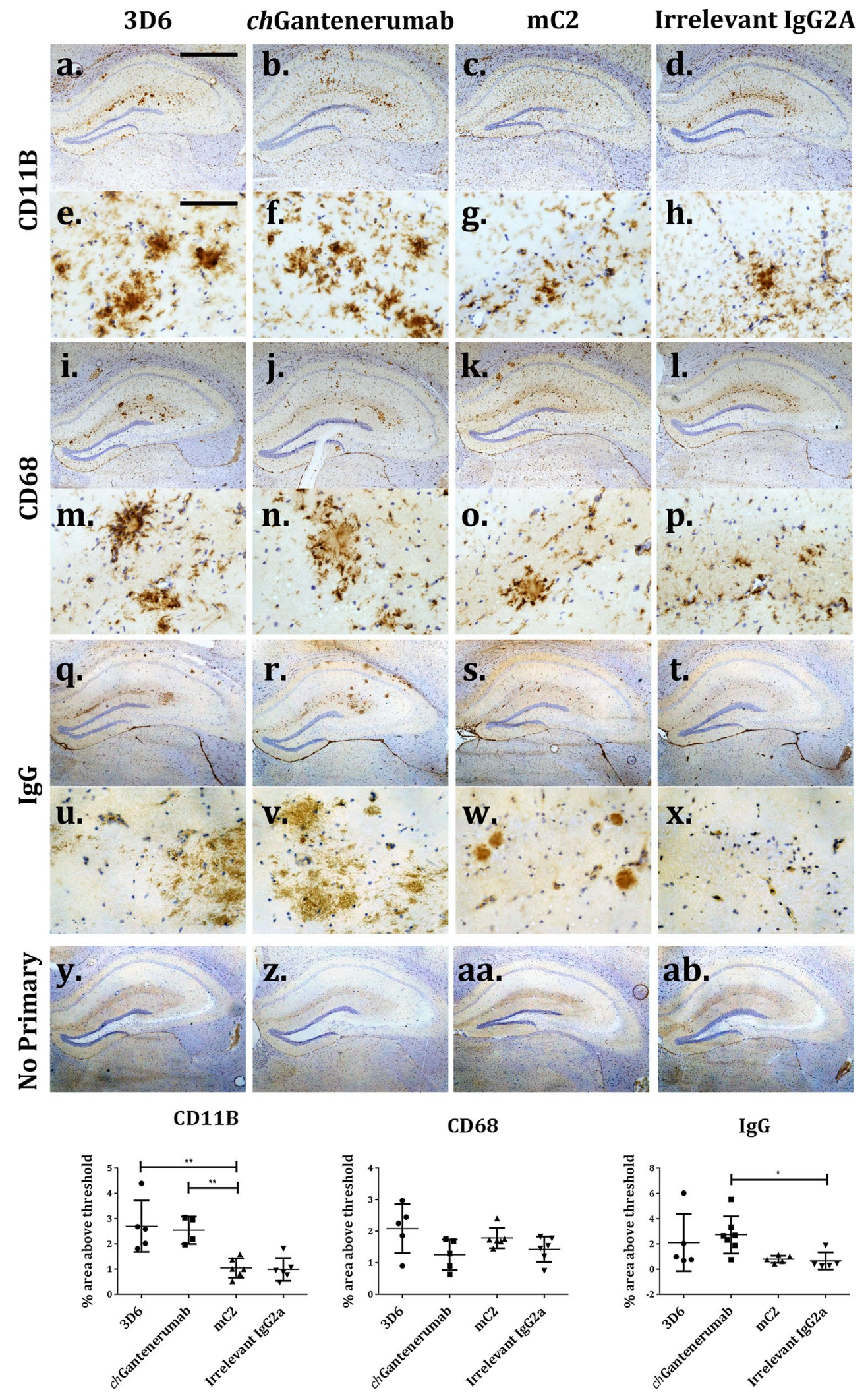



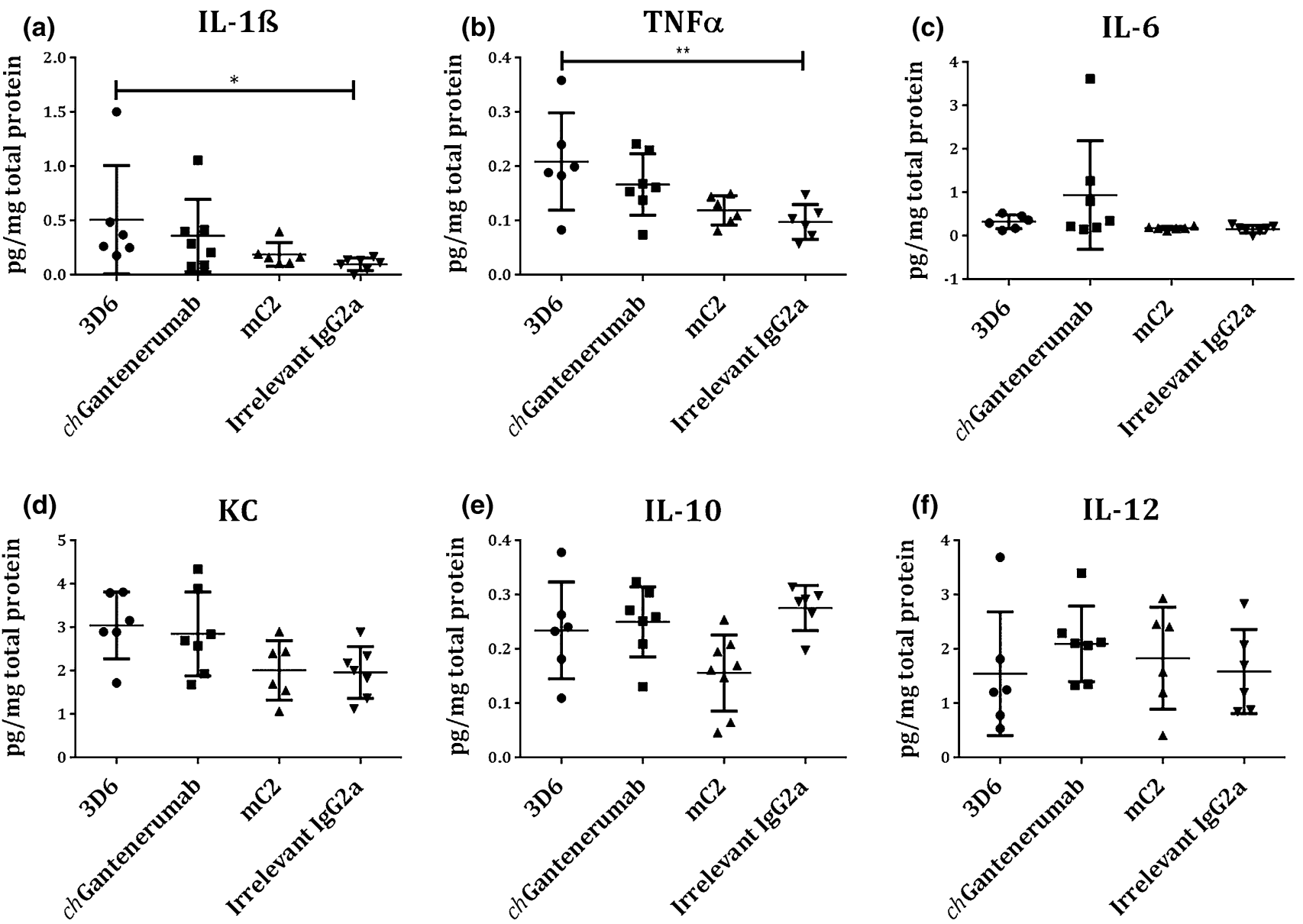

Fig. 5 Cytokine levels following intracranial injection of anti-A $\beta$ $\mathrm{mAbs}$. Cytokine levels were measured in homogenate made from hippocampal punches taken from $\mathrm{Tg} 2576$ mice injected with antibodies. Peptide levels were measured by multiplex ELISA and normalised to total protein concentration. a-f Cytokine levels in hippocampal

\section{Discussion}

There have been a number of high profile clinical disappointments for anti-A $\beta$ immunotherapy, with Bapineuzumab, Solanezumab, Crenezumab and Gantenerumab all failing to show disease-modifying effects in clinical trials. Differences in: epitope and affinities for $A \beta, F c \gamma R$ affinity and the pre-clinical models used for characterisation make direct comparison difficult. Therefore, to better understand the underlying biological mechanisms, we compared three highly characterised clinical candidates, Bapineuzumab, Gantenerumab and Crenezumab for their ability to clear plaques and induce neuroinflammation in an experimental model of Alzheimer's disease (Tg2576). We generated murine, recombinant versions of Bapineuzumab (3D6), Crenezumab (mC2) and a mouse/human chimeric version of Gantenerumab (chGantenerumab). These antibodies were produced using the same murine punches expressed as pg.mg total protein. Injection of 3D6 leads to significantly increased levels of pro-inflammatory cytokines $\mathrm{TNF} \alpha$ and IL- $1 \beta$ compared to IgG2a control ( $\mathbf{a} p=0.0042, \mathbf{b} p=0.0262)$. Data were analysed by one-way ANOVA and Tukey post hoc test $(n=6 / 7)$, and presented as mean $\pm \mathrm{SD}$

IgG2a constant regions, and were injected intracranially into 18-month $\mathrm{Tg} 2576$ mice. The murine IgG2a constant region is most similar to human $\mathrm{IgG} 1$ and has a strong ability to activate human Fc $\gamma$ Rs and induce inflammation [4]. We are not aware of previous studies that directly compare murinised versions of Bapineuzumab, Crenezumab and Gantenerumab for their ability to clear plaques and induce inflammation.

We show that all $\operatorname{IgG} 2 \mathrm{a}$ antibodies bind to recombinant immobilised peptide and plaques present in the $\mathrm{Tg} 2576$ brain tissue sections, with 3D6 displaying the highest relative affinity to $\mathrm{A} \beta$. The antibody chGantenerumab also bound with high affinity to immobilised $\mathrm{A} \beta$ peptide, but showed strong binding to neurons in cryosections of both transgenic and wild-type animals. $\mathrm{mC} 2$ was able to bind $\mathrm{A} \beta$ peptide in vitro and plaques in vivo, but the relative affinity was 100 -fold weaker than for 3D6. These observations are relevant for biological function, as 3D6, which had the 
strongest affinity for $A \beta$ plaques in our model, was the only antibody to significantly reduce $A \beta$ levels in vivo. Due to the potential of antigenic masking to affect the results from immunohistochemistry and MSD assay, we used Congo red staining and demonstrate that plaque numbers are reduced following 3D6 treatment. 3D6 injection also induced the activation of microglia as measured by their increase in CD11B expression and increased levels of the pro-inflammatory cytokines, IL- $1 \beta$ and TNF $\alpha$. One of the mechanisms of antibody mediated plaque clearance is through activation of microglia $\mathrm{Fc} \gamma \mathrm{Rs}$ and phagocytosis $[30,31]$. Crosslinking of Fc $\gamma$ Rs by immune complexes leads to switching to an "M2b" phenotype [18], characterised by the production of reactive oxygen species and pro-inflammatory cytokines, including IL- $1 \beta$ and TNF $\alpha$. The antibody subclass we used for this experiment, mouse $\operatorname{IgG} 2 \mathrm{a}$, is a potent inducer of inflammation due to its high affinity for activating receptors [5]. It has previously been shown that the IgG2a version of the anti-pyroglutamate $\mathrm{mE} 8$ is better at clearing plaques than the IgG1 version (with lower Fc $\gamma \mathrm{R}$ affinity), implying that $\mathrm{Fc} \gamma \mathrm{Rs}$ are involved in the clearance of plaques [10]. Gantenerumab did not significantly reduce the levels of $\mathrm{A} \beta$, but detection of mouse $\operatorname{IgG}$ bound to plaques provides clear evidence for target engagement. Like 3D6, increased expression of CD11B was observed but minimal change in CD68 expression levels suggest less efficient phagocytosis following injection of chGantenerumab. As all antibodies were generated as IgG2a isotypes, this lack of phagocytosis and plaque clearance is not due to lack of effector function, but rather dependent on the affinity and/or epitope. Bapineuzumab and Gantenerumab bind to residues in the $\mathrm{N}$ terminus of $A \beta$, crystal structures of Bapineuzumab in complex with $\mathrm{A} \beta$ show that it binds to amino acids $1-5$ which are in helical conformation [17]. Gantenerumab, in contrast, binds to a conformational epitope which also includes residues in the mid-domain [3]. chGantenerumab has a lower EC50 in our A $1-40$ binding ELISA, when compared to murine 3D6 ( 0.34 vs $0.17 \mathrm{pM}$, respectively) and therefore, clearance of plaques may require more time-this is supported by the changes in microglial phenotype and cytokine production. The antibody $\mathrm{mC} 2$ was unable to clear $A \beta$ plaques 7 days post-injection, but unlike chGantenerumab, this antibody did not induce any detectable changes in microglial phenotype or cytokine levels, despite having similar effector function. Immunoreactivity for mouse IgG strongly implies that the lack of clearance is due to poor plaque engagement, as IgG levels were not different from control IgG2a antibody. $\mathrm{mC} 2$ binds to a middomain epitope (AA 16-24) and studies of other antibodies that bind this region such as, m266 (Solanezumab), suggest that this epitope is inaccessible when $A \beta$ is in aggregated forms and this prevents antibodies like $\mathrm{m} 266$ from binding to and clearing plaques [11]. This is supported by binding to formic acid-treated sections, which shows that $\mathrm{mC} 2$ requires the solubilisation of plaques with formic acid to bind. Our results demonstrate that targeting the $\mathrm{N}$ terminus of $A \beta$ is more effective for plaque clearance. The ability of Crenezumab and Solanezumab to engage human $\mathrm{A} \beta$ in $\mathrm{AD}$ cases has previously been questioned, and cross-reactivity for a number of antigens has been reported [28]. We, however, found that $\mathrm{mC} 2$ was able to bind to $\mathrm{A} \beta$ in immunohistochemistry of human AD tissue. Antibodies that are unable to bind to $A \beta$ plaque without formic acid antigen retrieval may not be able to engage plaques in the brains of $\mathrm{AD}$ patients. The inability to engage plaques strongly may prevent the removal of aggregated $A \beta$ species from the brain following immunotherapy.

$\mathrm{AD}$ patients treated with Bapineuzumab or Gantenerumab have developed dose-limiting vascular side effects (ARIAs), but the underlying mechanisms are not completely understood. There is evidence that activation of microglia, and/or perivascular macrophages through Fc $\gamma R$ s and the subsequent neuroinflammation may be partly responsible for these side effects. It has been shown that reduced binding to $\mathrm{Fc} \gamma \mathrm{R}$ can decrease the incidence of vascular damage in mice $[6,13,29]$. In this study, we provide further experimental evidence that antibody engagement with activating $\mathrm{Fc} \gamma \mathrm{Rs}$ generates a pro-inflammatory response in the brain, as IgG2a versions of 3D6 and chGantenerumab both resulted in microglial activation and elevated cytokine production. The clinical candidate Crenezumab is built on a hIgG4 backbone, which has significantly reduced Fc $\gamma \mathrm{R}$ affinity compared to hIgG1. This was aimed to reduce the inflammatory response to immunotherapy and therefore reduce the associated side effects, and indeed ARIAs were not reported in patients treated with 10x the maximal dose of Bapineuzumab [1]. Our study provides an alternative explanation for the lack of side effects: the lack of plaque engagement by the antibody. We show that intracranial injection of an $\mathrm{IgG} 2$ a murine version of Crenezumab-mC2 failed to clear plaques or induce a pro-inflammatory response. These observations suggest that inflammation related to immunotherapy is not just dependant on the ability of the antibody to engage Fc $\gamma$ Rs but also on the epitope and ability of the antibody to engage plaques.

3D6 and $\mathrm{mC} 2$ are not exactly the same as the final clinical candidates; Bapineuzumab and Crenezumab. This could mean there are slight differences in the binding affinity which could influence the rate of $\mathrm{A} \beta$ clearance and inflammation; therefore, extrapolating these data should be done with caution. However, the clinical antibodies share the same epitope and are incredibly similar in sequence, and therefore the response is likely to be similar. Intra-cranial injection is a useful technique allowing rapid and costefficient characterisation of the response to an antibody, 
however, there are some limitations to this approach. To limit injection-mediated tissue damage, we use fine pulled glass capillaries to inject into the brain. However, even with caution any injection will cause some tissue damage, which may influence the subsequent immune response. Patients are not injected intracranially with these antibodies, and therefore, injecting directly into the brain is less relevant to the clinic than giving a systemic dose of the antibodies. One factor to consider is that the localised concentration of $\operatorname{IgG}$ following central injection will be higher than after systemic treatment, which could therefore influence the neuroinflammatory response. To fully characterise the differences between these antibodies, a systemic trial is needed which would also allow the measurement of cognitive changes. Previous studies have shown that there is variability in the response between different transgenic APP mouse models, in particular extensively aged mice, after treatment with anti-A $\beta$ antibodies [10, 33]. Therefore, further studies would be required to confirm the findings presented in this manuscript in different models. Furthermore, studies in transgenic APP mice have not always translated into successful clinical trials in humans; therefore, the response to the different anti- $\mathrm{A} \beta$ antibodies may differ in human AD patients.

We believe the results presented in the current manuscript can inform the development of optimised clinical antibodies. Treatment with 3D6 is effective at clearing plaques, however, part of this response causes increased neuroinflammation. Optimised immunotherapy for $\mathrm{AD}$ ideally separates phagocytosis and neuroinflammation, which would allow clearance of $A \beta$ without the induction of detrimental pro-inflammatory cytokine release. To achieve this, better understanding of the receptors involved in this processes is essential. We know that a range of different Fc $\gamma$ Rs is expressed in the brains of AD patients and mouse models $[8,14,21]$, but the physiological role of these receptors in the brain and their relative contribution to neuroinflammation and plaque clearance remain poorly understood. 3D6 has strong target binding and a high risk of causing vascular side effects and inflammation, therefore, to minimise toxicity reduction of its effector function will likely be beneficial. In contrast, $\mathrm{mC} 2$ with lower target binding might need stronger $\mathrm{Fc} \gamma \mathrm{R}$ binding to increase efficacy. Based on our results, we conclude that reduction of the effector function of Crenezumab did not have the expected beneficial effects, and the lack of clinical efficacy may be due to its lower plaque engagement. It is clear that we do not fully understand the role that $F c \gamma$ Rs play in the CNS (see recent review [14], as there is mounting evidence that these receptors play a specific role in the pathology of dementia. In humans, six Fc $\gamma$ Rs have been identified (activatory receptors, Fc $\gamma$ RI, IIa, IIc, IIIa, an inhibitory receptor Fc $\gamma$ RIIb and a GPI-linked decoy Fc $\gamma$ RIIIIb) and the ratio of activatory: inhibitory expression determines the activation threshold of effector cells [19]. Different receptors may play different roles in the clearance of $\mathrm{A} \beta$ or in the induction of side effects. Effector function of antibodies is critical to cancer immunotherapy, and much progress has been made in antibody engineering to develop therapeutic antibodies with improved binding to a particular receptor [7]. Better understanding of the role of specific $\mathrm{Fc} \gamma \mathrm{Rs}$ in immunotherapy may facilitate the modification of anti-A $\beta$ immunotherapies by antibody engineering to maximise plaque clearance and reduce side effects.

Acknowledgments We thank the medical research council (UK) for funding for James Fuller's studentship, and Lundbeck A/S for extra funding for animals and reagents. We also thank Susanne Lüder for her help in antibody production and: Kasper Larsen, Kate Pedersen and Dr. Anna Parachikova for help with the Tg2576 colony and stereotaxic surgery. Thank you to Dr. Delphine Boche and Dr Sonja Rakic for advice and help with regards to human immunohistochemistry, and Brain UK for AD brain tissue.

Open Access This article is distributed under the terms of the Creative Commons Attribution 4.0 International License (http://creativecommons.org/licenses/by/4.0/), which permits unrestricted use, distribution, and reproduction in any medium, provided you give appropriate credit to the original author(s) and the source, provide a link to the Creative Commons license, and indicate if changes were made.

\section{References}

1. Adolfsson O, Pihlgren M, Toni N, Varisco Y, Buccarello AL, Antoniello K, Lohmann S, Piorkowska K, Gafner V, Atwal JK et al (2012) An effector-reduced anti- $\beta$-amyloid $(A \beta)$ antibody with unique $A \beta$ binding properties promotes neuroprotection and glial engulfment of $A \beta$. J Neurosci 32:9677-9689. doi:10.1523/ jneurosci.4742-11.2012

2. Bard F, Cannon C, Barbour R, Burke RL, Games D, Grajeda H, Guido T, Hu K, Huang JP, Johnson-Wood K et al (2000) Peripherally administered antibodies against amyloid betapeptide enter the central nervous system and reduce pathology in a mouse model of Alzheimer disease. Nat Med 6:916-919. doi: $10.1038 / 78682$

3. Bohrmann B, Baumann K, Benz J, Gerber F, Huber W, Knoflach F, Messer J, Oroszlan K, Rauchenberger R, Richter WF et al (2012) Gantenerumab: a novel human anti-A beta antibody demonstrates sustained cerebral amyloid-beta binding and elicits cell-mediated removal of human amyloid-beta. J Alzheimers Dis 28:49-69. doi:10.3233/jad-2011-110977

4. Bruhns P (2012) Properties of mouse and human IgG receptors and their contribution to disease models. Blood 119:5640-5649. doi:10.1182/blood-2012-01-380121

5. Bruhns P, Iannascoli B, England P, Mancardi DA, Fernandez N, Jorieux S, Daeron M (2009) Specificity and affinity of human $\mathrm{Fc}$ gamma receptors and their polymorphic variants for human IgG subclasses. Blood 113:3716-3725. doi:10.1182/ blood-2008-09-179754

6. Carty NC, Wilcock DM, Rosenthal A, Grimm J, Pons J, Ronan V, Gottschall PE, Gordon MN, Morgan D (2006) Intracranial administration of deglycosylated C-terminal-specific anti-Abeta antibody efficiently clears amyloid plaques without activating 
microglia in amyloid-depositing transgenic mice. J Neuroinflamm 3:11. doi:10.1186/1742-2094-3-11

7. Chan AC, Carter PJ (2010) Therapeutic antibodies for autoimmunity and inflammation. Nat Rev Immunol 10:301-316. doi:10.1038/nri2761

8. Cribbs DH, Berchtold NC, Perreau V, Coleman PD, Rogers J, Tenner AJ, Cotman CW (2012) Extensive innate immune gene activation accompanies brain aging, increasing vulnerability to cognitive decline and neurodegeneration: a microarray study. J Neuroinflamm 9:179. doi:10.1186/1742-2094-9-179

9. DeMattos RB, Bales KR, Cummins DJ, Dodart JC, Paul SM, Holtzman DM (2001) Peripheral anti-A beta antibody alters CNS and plasma A beta clearance and decreases brain A beta burden in a mouse model of Alzheimer's disease. P Natl Acad Sci USA 98:8850-8855. doi:10.1073/pnas.151261398

10. DeMattos Ronald B, Lu J, Tang Y, Racke Margaret M, DeLong Cindy A, Tzaferis John A, Hole Justin T, Forster Beth M, McDonnell Peter C, Liu F et al (2012) A plaque-specific antibody clears existing $\beta$-amyloid plaques in Alzheimer's disease mice. Neuron 76:908-920. doi:10.1016/j.neuron.2012.10.029

11. Dodart JC, Bales KR, Gannon KS, Greene SJ, DeMattos RB, Mathis C, DeLong CA, Wu S, Wu X, Holtzman DM et al (2002) Immunization reverses memory deficits without reducing brain A beta burden in Alzheimer's disease model. Nat Neurosci 5:452457. doi: $10.1038 / \mathrm{nn} 842$

12. Doody RS, Thomas RG, Farlow M, Iwatsubo T, Vellas B, Joffe S, Kieburtz K, Raman R, Sun X, Aisen PS et al (2014) Phase 3 trials of solanezumab for mild-to-moderate Alzheimer's disease. N Engl J Med 370:311-321. doi:10.1056/NEJMoa1312889

13. Freeman GB, Brown TP, Wallace K, Bales KR (2012) Chronic administration of an aglycosylated murine antibody of ponezumab does not worsen microhemorrhages in aged $\mathrm{Tg} 2576$ mice. Curr Alzheimer Res 9:1059-1068

14. Fuller JP, Stavenhagen JB, Teeling JL (2014) New roles for Fc receptors in neurodegeneration - the impact on immunotherapy for Alzheimer's Disease. Front Neurosci 8:235. doi:10.3389/ fnins.2014.00235

15. Hardy J, Selkoe DJ (2002) Medicine - the amyloid hypothesis of Alzheimer's disease: progress and problems on the road to therapeutics. Science 297:353-356

16. Lunnon K, Teeling JL, Tutt AL, Cragg MS, Glennie MJ, Perry VH (2011) Systemic inflammation modulates Fc receptor expression on microglia during chronic neurodegeneration. J Immunol 186:7215-7224. doi:10.4049/jimmunol.0903833

17. Miles LA, Crespi GAN, Doughty L, Parker MW (2013) Bapineuzumab captures the N-terminus of the Alzheimer's disease amyloid-beta peptide in a helical conformation. Sci Rep 3:1302. doi:10.1038/srep01302

18. Mosser DM, Edwards JP (2008) Exploring the full spectrum of macrophage activation. Nat Rev Immunol 8:958-969

19. Nimmerjahn F, Ravetch JV (2008) Fcgamma receptors as regulators of immune responses. Nat Rev Immunol 8:34-47. doi:10.1038/nri2206

20. Orgogozo JM, Gilman S, Dartigues JF, Laurent B, Puel M, Kirby LC, Jouanny P, Dubois B, Eisner L, Flitman S et al (2003) Subacute meningoencephalitis in a subset of patients with $\mathrm{AD}$ after $\mathrm{A}$ beta 42 immunization. Neurology 61:46-54

21. Peress NS, Fleit HB, Perillo E, Kuljis R, Pezzullo C (1993) Identifcation of Fc gamma RI, II and III on normal human brain ramified microglia in senile plaques in Alzheimer's Disease. J Neuroimmunol 48:71-80. doi:10.1016/0165-5728(93)90060-c

22. Rinne JO, Brooks DJ, Rossor MN, Fox NC, Bullock R, Klunk WE, Mathis CA, Blennow $\mathrm{K}$, Barakos J, Okello AA et al
(2010) (11)C-PiB PET assessment of change in fibrillar amyloid-beta load in patients with Alzheimer's disease treated with bapineuzumab: a phase 2, double-blind, placebo-controlled, ascending-dose study. Lancet Neurol 9:363-372. doi:10.1016/ s1474-4422(10)70043-0

23. Salloway S, Sperling R, Fox NC, Blennow K, Klunk W, Raskind M, Sabbagh M, Honig LS, Porsteinsson AP, Ferris S et al (2014) Two phase 3 trials of bapineuzumab in mild-to-moderate Alzheimer's disease. N Engl J Med 370:322-333. doi:10.1056/ NEJMoa1304839

24. Salloway SP, Black R, Sperling R, Fox N, Gilman S, Schenk D, Grundman M (2010) A phase 2 multiple ascending dose trial of bapineuzumab in mild to moderate Alzheimer disease reply. Neurology 74:2026-2027

25. Schenk D, Barbour R, Dunn W, Gordon G, Grajeda H, Guido T, Hu K, Huang JP, Johnson-Wood K, Khan K et al (1999) Immunization with amyloid-beta attenuates Alzheimer diseaselike pathology in the PDAPP mouse. Nature 400:173-177. doi: $10.1038 / 22124$

26. Sudduth TL, Greenstein A, Wilcock DM (2013) Intracranial injection of Gammagard, a human IVIg, modulates the inflammatory response of the brain and lowers A beta in APP/PS1 mice along a different time course than anti-A beta antibodies. J Neurosci 33:9684-9692. doi:10.1523/jneurosci.1220-13.2013

27. Teeling JL, Carare RO, Glennie MJ, Perry VH (2012) Intracerebral immune complex formation induces inflammation in the brain that depends on $\mathrm{Fc}$ receptor interaction. Acta Neuropathol 124:479-490. doi:10.1007/s00401-012-0995-3

28. Watt AD, Crespi GAN, Down RA, Ascher DB, Gunn A, Perez KA, McLean CA, Villemagne VL, Parker MW, Barnham KJ et al (2014) Do current therapeutic anti-A beta antibodies for Alzheimer's disease engage the target? Acta Neuropathol 127:803-810. doi:10.1007/s00401-014-1290-2

29. Wilcock DM, Alamed J, Gottschall PE, Grimm J, Rosenthal A, Pons J, Ronan V, Symmonds K, Gordon MN, Morgan D (2006) Deglycosylated anti-amyloid-beta antibodies eliminate cognitive deficits and reduce parenchymal amyloid with minimal vascular consequences in aged amyloid precursor protein transgenic mice. J Neurosci Off J Soc Neurosci 26:5340-5346. doi:10.1523/ JNEUROSCI.0695-06.2006

30. Wilcock DM, DiCarlo G, Henderson D, Jackson J, Clarke K, Ugen KE, Gordon MN, Morgan D (2003) Intracranially administered anti-Abeta antibodies reduce beta-amyloid deposition by mechanisms both independent of and associated with microglial activation. J Neurosci Off J Soc Neurosci 23:3745-3751

31. Wilcock DM, Munireddy SK, Rosenthal A, Ugen KE, Gordon MN, Morgan D (2004) Microglial activation facilitates Abeta plaque removal following intracranial anti-Abeta antibody administration. Neurobiol Dis 15:11-20

32. Wilcock DM, Rojiani A, Rosenthal A, Levkowitz G, Subbarao S, Alamed J, Wilson D, Wilson N, Freeman MJ, Gordon MN et al (2004) Passive amyloid immunotherapy clears amyloid and transiently activates microglia in a transgenic mouse model of amyloid deposition. J Neurosci Off J Soc Neurosci 24:6144-6151. doi:10.1523/JNEUROSCI.1090-04.2004

33. Wilcock DM, Zhao Q, Morgan D, Gordon MN, Everhart A, Wilson JG, Lee JE, Colton CA (2011) Diverse inflammatory responses in transgenic mouse models of $\mathrm{AD}$ and the effect of immunotherapy on these responses. ASN Neuro 3(5):249-258. doi 10.1042/AN20110018 